\title{
SURGICAL AND PATHOLOGICAL CHANGES AFTER RADIOFREQUENCY ABLATION OF THYROID NODULES
}

\author{
Chiara Dobrinja1, Stella Bernardi², Bruno Fabris², Rita Eramo1, Petra Makovac1, Gabriele Bazzocchi3, \\ Fabrizio Zanconati2, Fulvio Stacul ${ }^{3}$
}

(1) General Surgery, Cattinara Teaching Hospital, Trieste, Italy

(2) Department of Medical, Surgical and Health Sciences, University of Trieste, Trieste, Italy

(3) Radiology Unit, Maggiore Hospital, Trieste, Italy

INTRODUCTION: Radiofrequency ablation (RFA) is not only an effective but also a reasonably safe treatment option for benign thyroid nodules causing cosmetic concerns, local pain, hyperthyroidism [1]. However, since RFA is relatively new, some concerns on its outcomes still exist. For example would RFA jeopardize a subsequent operation and/or hinder histological diagnosis? Here we present the 2-year follow-up results of 70 patients who underwent RFA. Because of nodule regrowth, two of these patients underwent sugery after being treated with RFA.

OBJECTIVE: The aim of this study was to describe the surgical and pathological changes of the thyroid nodules that were initially treated with RFA and then, due to their regrowth, were surgically removed.

METHODS: This is a retrospective study on the 2-year follow-up results of 64 patients with Thy 2 thyroid nodules and 6 patients with Thy3 nodules (case 1-6) who underwent a single session of RFA. Thy2 nodules were selected according to current recommendations [2]. The Thy3 nodules treated with RFA were symptomatic nodules in high-risk individuals or patients refusing surgery. These patients did not have family history of thyroid cancer, did not present suspiciuos lymph nodes, and had single thyroid nodules, unchanged over the last three years, with no calcifications, and no evidence of nuclear atypia. Since two Thy 3 nodules (case 1, case 2) regrew after RFA, the patients underwent surgery. Both RFA and surgery were performed as already described [3]. Patients signed an informed consent before the procedure/s and in order to use their clinical data for scientfic purposes.

\section{RESULTS:}

Characteristics of all the patients

\begin{tabular}{lccc}
\hline Characteristics & $\begin{array}{c}\text { Thy2 } \\
(\mathbf{n = 6 4 )}\end{array}$ & $\begin{array}{c}\text { Thy3 } \\
(\mathbf{n = 6})\end{array}$ & $\boldsymbol{p}$ value \\
\hline Age (years) & $60.47 \pm 1.89$ & $61.16 \pm 5.62$ & n.s. \\
Sex (M) & 17 & 3 & n.s. \\
$\begin{array}{l}\text { Nodule max diameter } \\
\text { (mm) }\end{array}$ & $36.04 \pm 2.40$ & $38.17 \pm 4.12$ & n.s. \\
Nodule volume (mL) & $13.81 \pm 1.86$ & $17.46 \pm 5.57$ & n.s \\
Solidity $>\mathbf{5 0 \%}$ & 55 & 6 & n.s \\
Solidity < 50\% & 9 & 0 & n.s. \\
BRAF mutations & Not tested & Absent & - \\
NRAS mutations & Not tested & Absent & - \\
TSH $(\boldsymbol{\mu U} / \mathbf{m L})$ & $1.35 \pm 0.23$ & $1.41 \pm 0.47$ & n.s. \\
Calcitonin $(\mathbf{p g} / \mathbf{m L})$ & $1.62 \pm 0.14$ & $1.42 \pm 0.36$ & n.s. \\
\hline
\end{tabular}

Characteristics of the patients with Thy3 nodules

\begin{tabular}{|c|c|c|c|c|c|c|}
\hline Characteristics & Case 1 & Case 2 & Case 3 & Case 4 & Case 5 & Case 6 \\
\hline Age (years) & 71 & 60 & 50 & 53 & 79 & 42 \\
\hline Sex & M & $\mathrm{F}$ & $\mathrm{F}$ & $\mathrm{F}$ & M & M \\
\hline $\begin{array}{l}\text { Nodule max } \\
\text { diameter }(\mathrm{mm})\end{array}$ & 53 & 42 & 41 & 38 & 32 & 23 \\
\hline $\begin{array}{l}\text { Nodule volume } \\
(\mathrm{mL})\end{array}$ & 40 & 24 & 19 & 11 & 7 & 2 \\
\hline Type of nodule & Solid nodule & Solid nodule & Solid nodule & Solid nodule & Solid nodule & Solid nodule \\
\hline FNAB & Thy 3 & Thy 3 & Thy 3 & Thy 3 & Thy3 & Thy3 \\
\hline BRAF mutations & Absent & Absent & Absent & Absent & Absent & Absent \\
\hline NRAS mutations & Absent & Absent & Absent & Absent & Absent & Absent \\
\hline TSH $(\mu \mathrm{U} / \mathrm{mL})$ & 1.38 & 1.94 & 1.22 & 0.65 & 0.02 & 3.35 \\
\hline $\begin{array}{l}\text { Calcitonin } \\
(\mathrm{pg} / \mathrm{mL})\end{array}$ & 1.3 & 1 & 1 & 1 & 1 & 3.2 \\
\hline Anti-TPO and/or & Absent & Absent & Absent & Absent & Absent & Absent \\
\hline
\end{tabular}

Volume reduction of Thy2 $(n=64)$ and Thy3 $(n=6)$ nodules

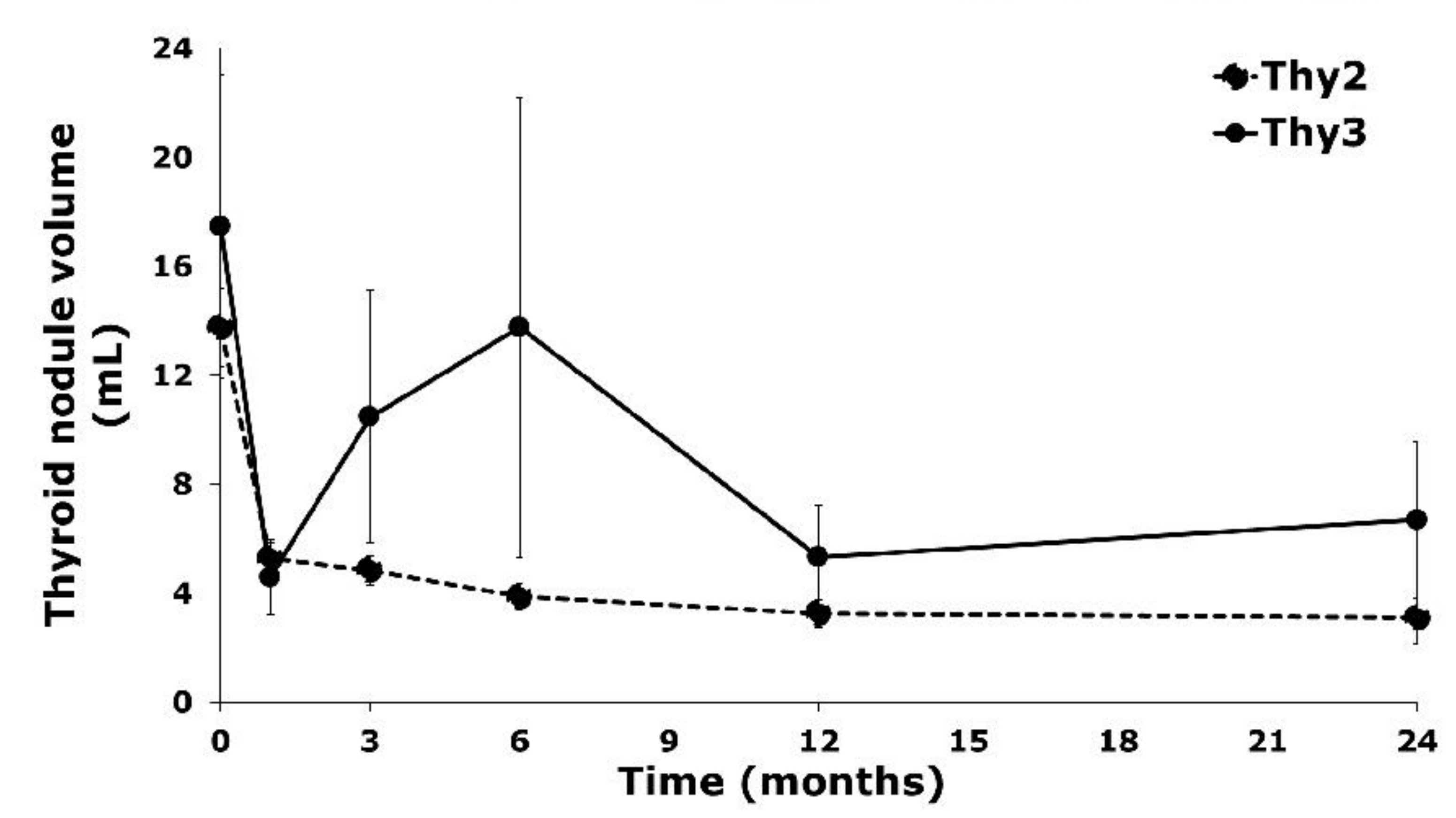

Case 1 histology (follicular carcinoma)

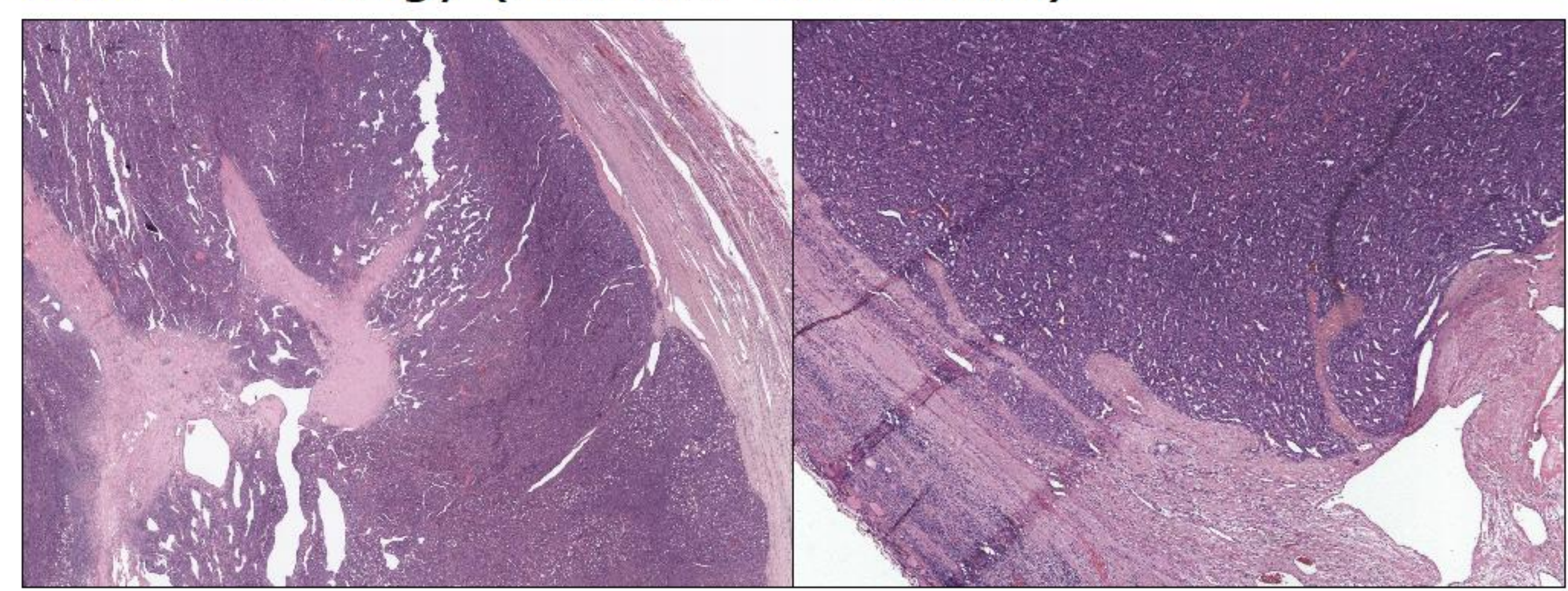

Volume reduction of each Thy3 nodule (cases 1-6)

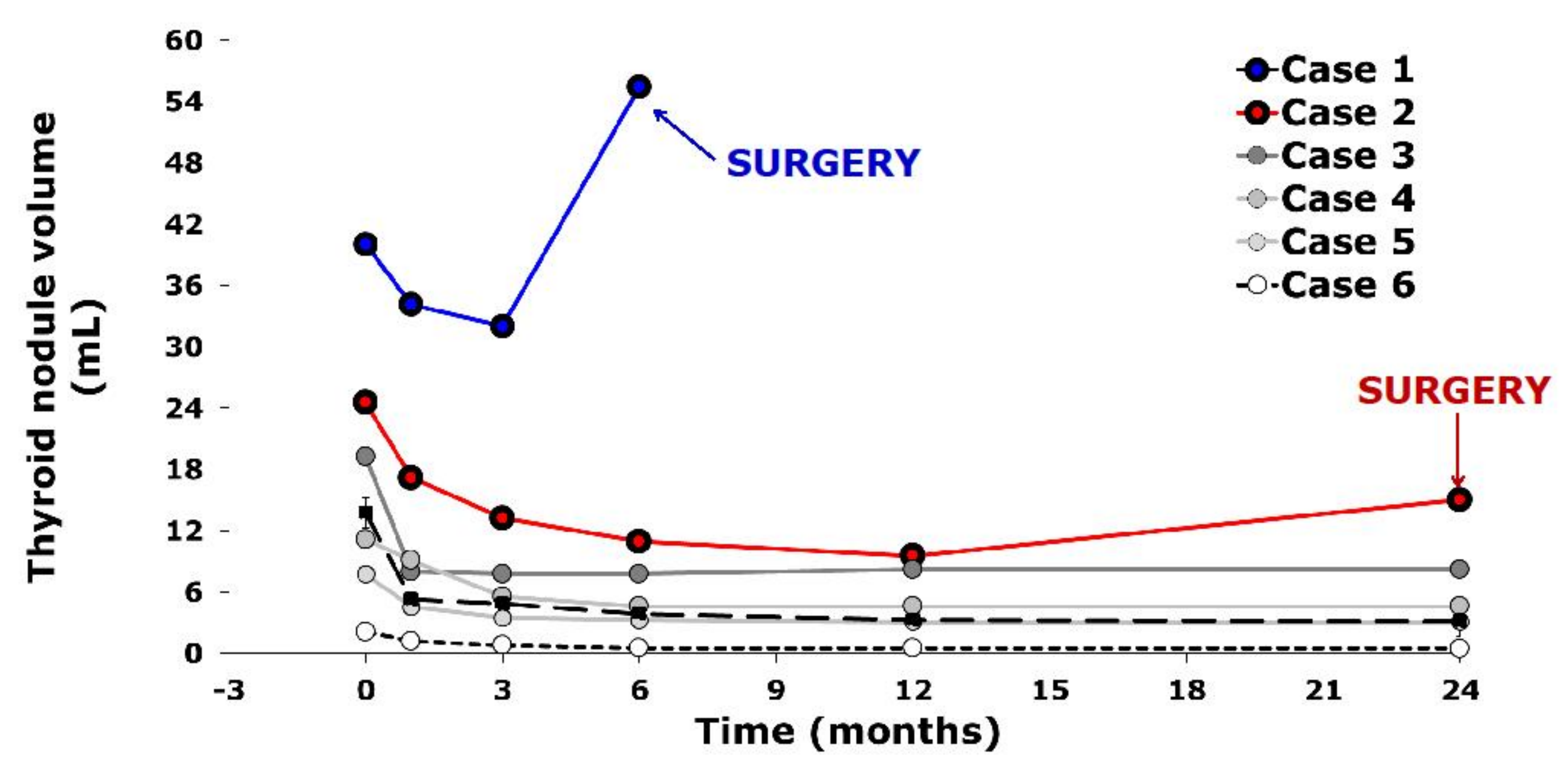

Case 2 histology (follicular neoplasm)



CONCLUSIONS: RFA is effective for the treatment of Thy2 nodules, but it should not be recommended for the treatment of Thy3 nodules, independently from their mutational status, as it delays surgery in case of malignancy. Nevertheless, here we show for the first time that one session of RFA does not affect subsequent thyroid surgery and/or histological diagnosis.

REFERENCES: [1] Gharib H et al, Journal of Clinical Endocrinology and Metabolism, 2013; 98 (10): 3949-3957

[2] Na DG et al, Korean Journal of Radiology 2012; 13(2): 117-125

[3] Bernardi S et al, International Journal of Endocrinolgy, 2014: 934595 